\title{
PROCESS OPTIMIZATION OF PRESSURE DIE CASTING TO ELIMINATE DEFECT USING CAE SOFTWARE
}

\author{
Vinod V Rampur ${ }^{1}$ \\ Assistant professor, Department of mechanical engineering, PESITM Shimoga, Karnataka, India
}

\begin{abstract}
Die Casting is the manufacturing process by which a liquid material is pressurized in to the mould, which contains a hallow cavity of the desired shape, and then molten metal is allowed to solidify. The solidified part is known as casting which is ejected or broken out to complete the process. Objective in this project is to develop tools, dies and gating system. Identify defects such as gas defects, shrinkage cavities, and mould material defects, pouring material defects, metallurgical defects etc. and take measures to reduce flaws by using CAE software. To reduce the amount airs entrapped in the mould by changing the gating system, runner and overflow location and optimize the gating system and process parameters for best quality product and improved productivity. Defects can be formed easily at critical location during pressure die casting of aluminium alloy part. It has defective effect on the casting. Mould filling and solidification process of a part was simulated using Z-cast software.
\end{abstract}

Key Words: Casting, HPDC, Z-cast, CAE Software, Simulation.

\section{INTRODUCTION}

Die Casting is the manufacturing process by which a liquid material is pressurized in to the mould, which contains a hallow cavity of the desired shape, and then molten metal is allowed to solidify. The die casting alloys ranges from those of low fusion alloys: Tin, Lead and Zinc. High fusion alloys: Aluminium, Magnesium and Copper. For low fusion alloys it is possible to employ hot chamber machines, high fusion alloys employ cold chamber machines.

High Pressure Die Casting (HPDC) suitable for the production of large numbers of small and medium size components requiring high dimensional accuracy and complex geometry and also used for low cost components.

\section{OBJECTIVES}

1. To develop tools, dies and gating system.

2. Identify defects such as gas defects, shrinkage cavities, mould material defects, pouring material defects and metallurgical defects.

3. To reduce the amount air entrapped in the mould by changing the gating system and runner riser location.

4. The analysis is carried out for the filling rate and the solidification rate. In the filling analysis it is observed that all the intricate shapes are filled and is compensated with suitable overflows.

5. Thus the project involves the design and analysis of the entire tool taking into account the various factors that might affect the functionality of the tool. Also the manufacturing details and the defects occurring during the process are studied and optimized.

\section{CASTING SIMULATION}

Computer aided design and simulation of casting were once considered today it has become an integral part of foundry operations, necessary to achieve consistently high quality castings with optimal yield.

All new and expanding foundries are planning casting simulation as an essential facility like melting and moulding units. A recent survey of maximum foundries using $\mathrm{CAD} / \mathrm{CAM}$ and simulation to reduced the average lead time for casting of particular product.

\subsection{NEED FOR SIMULATION}

Casting simulation should be used only when one of the following three factors can be justified, they are; Cost benefits obtained by casting simulation can be estimated, they are,

- Improve Quality of product: Improve the quality means decrease defect product and to meet desired properties.

- Improvement in production: Reduce cost per each casting to improve the production rate.

- Product Development: By using some simulation software to reduce virtual trails and improvement in development of casting.

\subsection{SETTING UP A SIMULATION FACILITY}

Three types of resources are required for setting up a casting simulation facility i.e., hardware, software and human ware. The choice of hardware is dependent on software. The choice of software is dependent on the requirement of the foundry and the person available for running the software. 


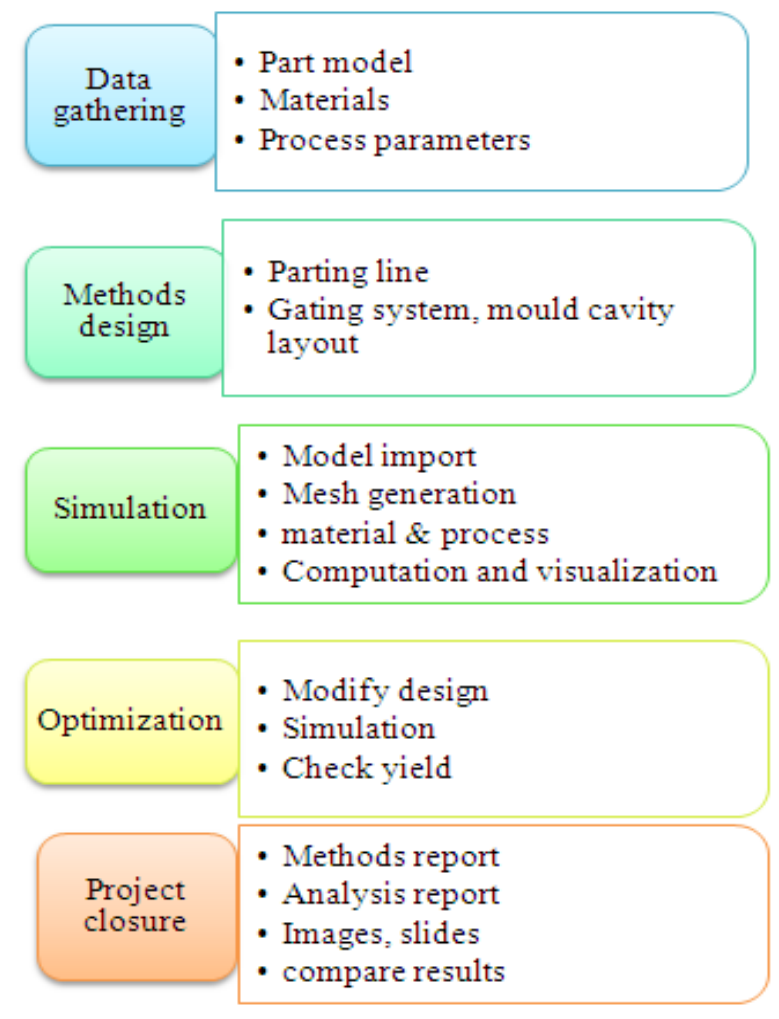

Data gathering: This is the initial stage of analysis, incomplete data will give inaccurate simulation and wrong conclusions. The following inputs are required before simulations are,Identify the Headings

a) CAD model of casting.

b) Initially with the available drafting of the component develop a 3D model using CAD software's like CATIA. The model should be saved in an exchange standard like STL.

c) Material properties.

d) As per the requirement of the component suitable material is selected and details related to cast metal and mould are gathered. Properties of all major alloys are usually available in the programme database.

e) Process parameters like pouring time and temperature are taken into consideration before casting simulation is carried out.

Design and modeling: The operator before simulation first design the following procedure i.e., locating of parting line, designing and locating of cores, runners, risers and gating system and also designing the mould cavity using his experience and foundry practices. This requires both knowledge and CAD skills. After completion of each round of simulation, the methods design has to be modified based on the results and the solid model of the mould has to be created again.

Numerical simulation: First carry out the following steps before simulating i.e., mould generation, mesh generation, material selection for mould and casting, specifying the temperature for mould and metal, specifying the die-cast details, specifying gravity direction. Now carry out the simulation, after the simulation is complete the defects in casting can be identified.
Optimization: This stage involves improving the methods design to eliminate defects and improve yield. The result obtained in first simulation is analyzed, and then suitable changes and improvements are done. The changes include redesigning gating system and improvements include providing overflows.

Project closure: This stage is achieved on reaching a simulation result where defects are reduced to the maximum possible limit. After achieving the solution to the problem documentation of the results is carried out. The documentation includes input and output data and pictures of defects and results.

\section{METHODOLOGY}

\section{Process flow chart:}
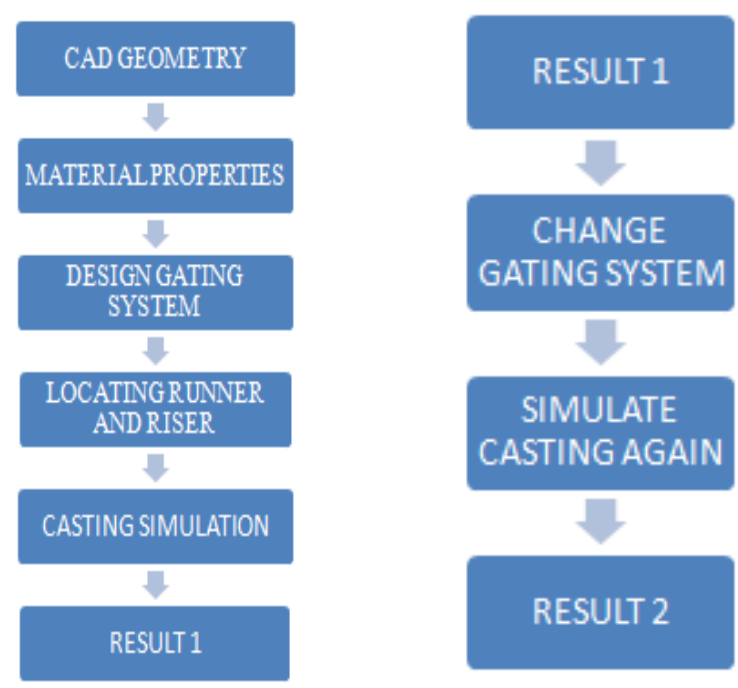

- First select the product or component for which the pressure die casting process is to be carried out.

- Develop CAD model of the product using applications such as Auto-cad, Catia from the isometric sketch provided by the company.

- According the working environment and properties required for the component select suitable material to suit the needs.

- Develop gating system that provides obstruction free flow of the liquid material through the component.

- Input specific details that are required for die casting simulation. Simulate the component using Z-cast software developed by cubictek, Korea.

- Check the result at the end of simulation.

- Identify flaws and modify gating system and provide overflows to get defect free result.

- The above steps will be repeated till we obtain defect free simulation [3]. 


\section{COMPONENT - HORN COVER}
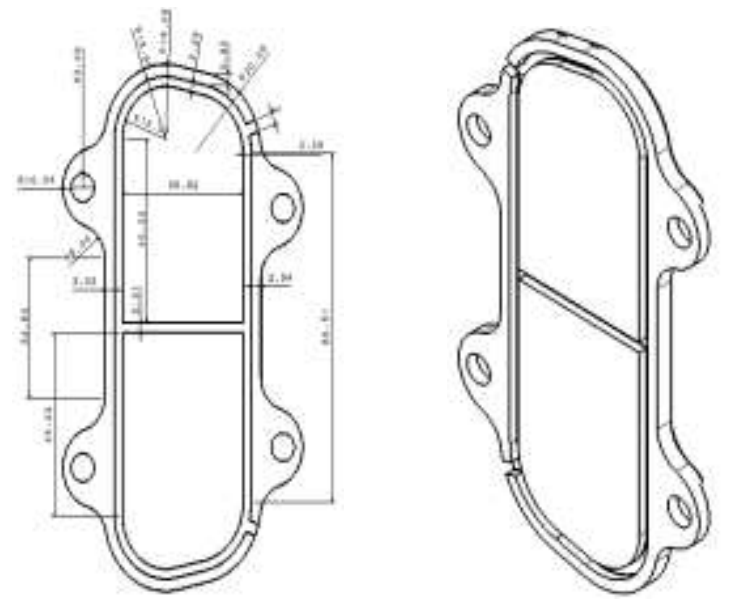

Horn cover is an automotive part. The material to be cast is an aluminium alloy -ACD12.The part to be cast has several intricate profiles such as holes, rectangular profiles, fillets etc. All these features are examined carefully and the design is carried out suitably. The parting line is chosen to suit easy manufacturability and to ensure high rate of production.

i) Pre-processor

- Open new workspace and save it with a specific file name.

- Open the STL files of the Horn cover component, runner and overflows.

- Add mould to the component.

- Generate mesh for the component.

ii) Solver

- Add suitable material for both component and mould that is available in the database.

- Specify the temperatures of both component material and mould.

- Selection of the in-gate.

- Specify the gravity direction in the component.

- Specify shrieked portion temperature.

- Specify temperature, velocity and filling time.

- Post processor

- Specify the flow temperature range.

- Select die cast as the in-gate parameter and input its values.

\section{EXPERIMENTAL INPUT DATA}

\section{Geometry}

- Solid model of Part ( Pro/E or UG part files, Step, igs or Para solid)

- Solid model of Die.

- Solid models of gating, Runner, and shot sleeve.

- Overall die dimension.

- Location of cooling lines.

- Location and dimensions of any slides, overflows, chills, cores.

- Layout showing number of parts/cavity.
- Gating, Runner, and shot sleeve dimensions and locations.

\section{Material Data}

- Standard alloy designation; chemistry of specific alloy - ADC12

- Die material -HDS BHOLER-W-302.

- Identification of any other materials used.

\section{Fluid Analysis}

- Fill time. -0.06sec

- Velocity $-1^{\text {st }}$ Stage Velocity $\mathbf{- 0 . 2 m} / \mathbf{s e c}$ $2^{\text {nd }}$ Stage velocity- $\mathbf{2 m} / \mathbf{s e c}$

- Injection Pressure- $280 \mathrm{Kg} / \mathrm{cm}^{2}$

- System pressure- $150 \mathrm{Kg} / \mathrm{cm}^{2}$

\section{Initial Temperature}

- Metal temperature at the time of cost Pouring temperature $=640^{\circ} \mathrm{C}$,

- Die preheat temperature: Initial $=150^{\circ}$ Stabilized $=$ $180^{\circ}$ cover die, $220^{\circ} \mathrm{EJE}$.

- $\quad$ Ambient temperature $=30^{\circ}$

- Water flow rate- 2Litter/mint./CHANNEL, IN SPOT COOLING 1 litter/min

- If not continuous, time on; time off Inlet $28^{\circ}$ and Outlet temperature $32^{\circ}$

\section{Cycle time}

\section{Start cycle (time 0)}

Time to complete

- Metal Injection - Start

$6 \mathrm{sec}$

- Dwell (hold) time

$14 \mathrm{sec}$

- Die opening time

$18 \mathrm{sec}$

- Begin spray

$24 \mathrm{sec}$

- End spray

- Begin Air Blow

$33 \mathrm{sec}$

- End Air blow

$36 \mathrm{sec}$

- Close die $45 \mathrm{sec}$

- Start of next cycle $50 \mathrm{sec}$

- Total cycle time: (die close to die close)

\subsection{RESULT AND DISCUSSIONS}

\section{Result 1}

The geometry of the gating system has been developed to analyze the casting pattern using the Z-cast software. 

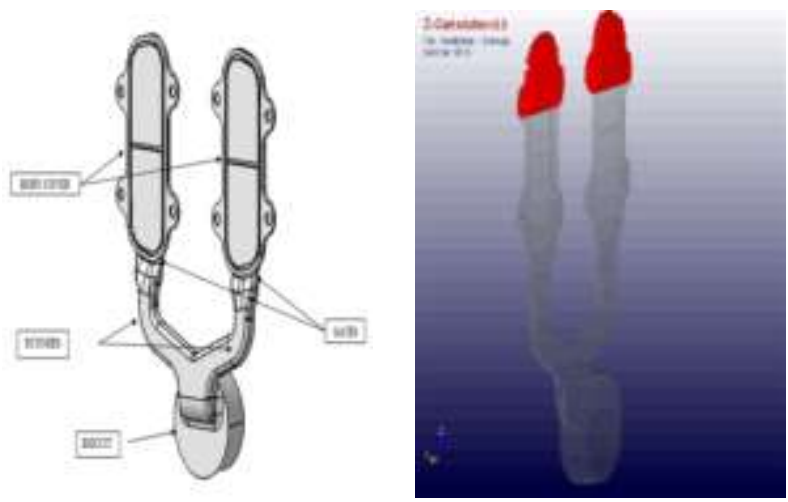

Horn cover with proper gating systems taking design considerations. The set up is designed in such a way that two components produce at the same time. Based on the number of cavities and the component shape parting line is located. On the basis of parting line gating is located. The component size is considerably small hence we use a side gate.

\section{Result 2:}
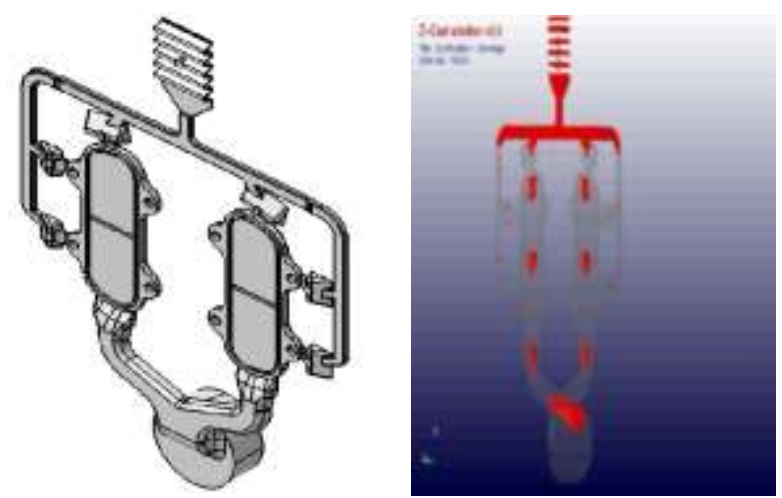

Filling regions in the casting after solidification of molten metal. The purpose of providing overflow is to reduce unfilling but in this case air entrapped in the top overflow section returns back into the mould cavity through the side entrance of the overflow. In the next case this concept has to be taken into consideration while designing the overflow.

\section{Final Result 3:}
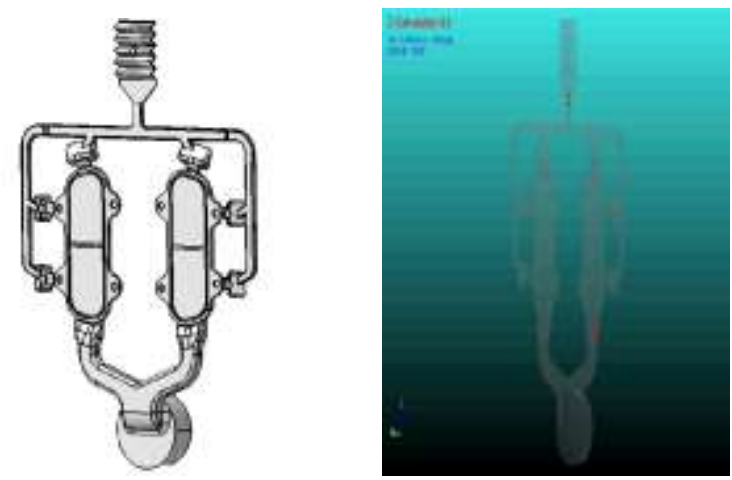

Component with gating system with modified overflows to get improved output from previous results. Here a step is provided where the overflow was broken in previous result, due to this change in overflow the blocks air from entering into the component.

\section{FINAL COMPONENT AFTER CASTING:}
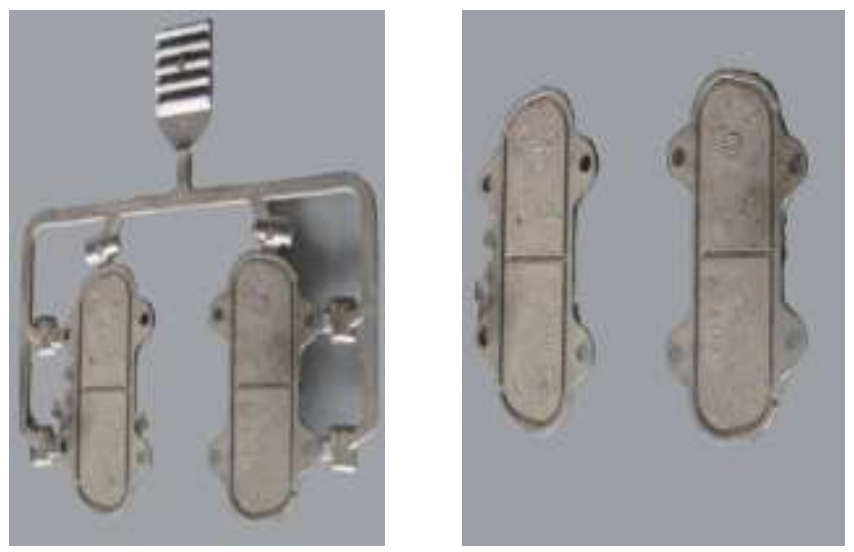

The casting shown are die casted using the final geometry wherein the accuracy of the casting is almost near to the predicted by analysis

\section{CONCLUSION}

- Increase the quality of product by reducing air present in the shot sleeve during casting process.

- HPDC machines are used to reduce set up time before casting process.

- Optimizing the casting process by controlling flow of molten metal in casting process by plunger movement.

- Less time for tool design process and minimum time will be required for casting process and wastage of material will be less.

- Simulation which gives the information to the user about the quality of the product whether acceptable or not.

- By use of HPDC machines, according to these simulation results, to reduce scrap, wastage, and production time and improve the quality of product.

- By using simulation result manufacturer can design the gates, runner and riser position, where to give overflow. By this to get best solution for filling up of molten metal in to mould cavity.

\section{ACKNOWLEDGMENT}

I express my sincere thanks and heartfelt gratitude to my guide Dr.T.R.Anil for the enthusiasm and inspiration. I express my deep sense of gratitude and heartfelt thanks to Prof. V.N. Satwik and Prof. S. C. Kulkarni for his attention, guidance, insight, and support during this project work and the preparation of this thesis. I also would like to express my deep sense of gratitude to Dr. R. R. Malagi, PG coordinator, department of Mechanical Engineering, for his valuable suggestions during this project work and the preparation of this thesis. 


\section{REFERENCES}

[1] Dargusch M.S., Dour.G, Schauer.N, Dinnis C.M., Savage G., The influence of pressure during solidification of high pressure die cast aluminium telecommunications components, J. Mater. Process. Technol. 180 (1-3) (2006) 37-43.

[2] Reddy A.P, Pande S.S and Ravi B., IIT - Bombay, "Computer Aided Design of die casting dies"

[3] Muthu kumar. B., "Design and development of pressure die casting", GT\&TC, Bengaluru

[4] Herman E.A, Heat Flow in the Die Casting Process, Society of Die Casting Engineers, 1985. 